CHANGE IN THE BASIC EARNINGS BY REGION

I ESPECIAL VAREJO • TRÊS GRANDES DESAFIOS PARA O VAREJO DO FUTUURO

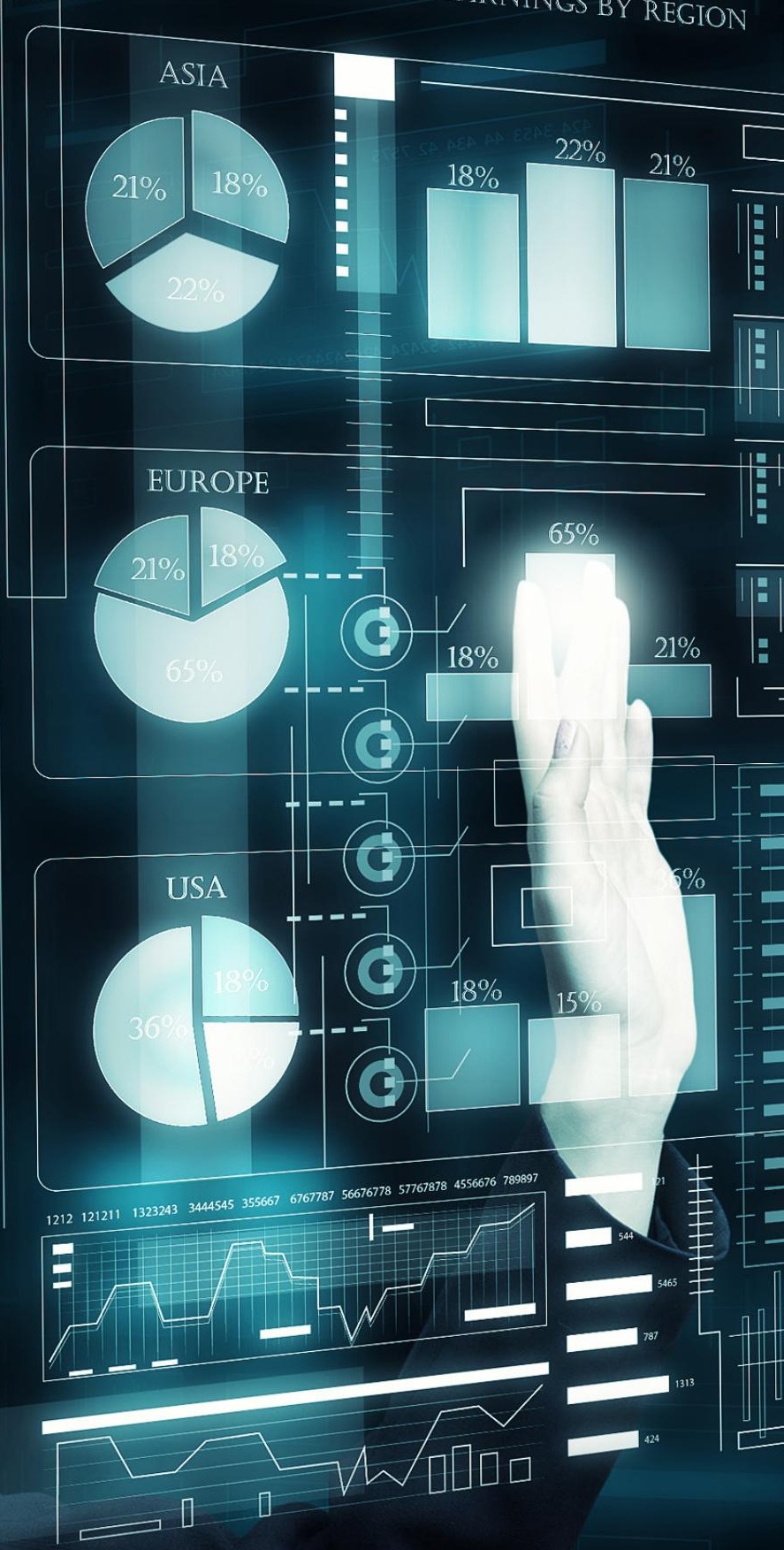




\section{TRÊS GRANDES DESAFIOS PARA O VAREJO DO FUTURO}

| POR MAURÍCIO MORGADO

\section{Será preciso lidar com um processo de compra cada vez menos previsível, administrar um volume de informações gigante e encontrar novas funções para as lojas físicas.}

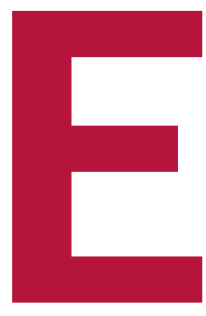

m 1850, surgiam as primeiras lojas de departamentos do mundo, como a francesa Bon Marchè e a norte-americana Marshall Fields. Entre 1920 e 1930, nasceram os primeiros supermercados e shopping centers, nos Estados Unidos. Em 1994, inaugurou-se o e-commerce quando a Pizza Hut passou a aceitar encomendas online. Desde então, com a expansão da internet e, mais recentemente, com o surgimento dos dispositivos móveis, a maneira como os consumidores se relacionam com as marcas mudou radicalmente. Os antigos formatos de varejo não desapareceram e, provavelmente, vão continuar existindo, mas varejistas de todas as modalidades precisarão se adaptar à nova onda de mudança, ou morrerão.

As novas tecnologias digitais trazem grandes dúvidas para os varejistas. Os recursos exigidos não são baixos, e os retornos ainda parecem incertos. Mesmo o maior site de vendas do mundo, a Amazon, por exemplo, vendeu seu primeiro livro em 1995, mas só conseguiu começar a lucrar em 2003. Para sobreviver nesse cenário, será preciso priorizar investimentos em inovações que realmente adicionem valor aos consumidores e, ao mesmo tempo, melhorem a eficiência das operações.

São três os principais desafios para o varejo no futuro. O primeiro é lidar com um processo de compra mais complexo e imprevisível, envolvendo lojas físicas, virtuais e redes sociais. O segundo está em administrar o imenso volume de dados que está sendo gerado. E o terceiro, mais desafiador ainda, é definir qual será o papel da loja física nesse novo mundo. Vamos a cada um deles.

\section{NOVA JORNADA DE COMPRAS}

Processos de compra que antes dependiam basicamente da conversa com amigos, anúncios na mídia de massa e visitas às lojas hoje podem começar no smartphone, passar por lojas físicas e terminar no computador pessoal. Isso sem contar a influência das mídias sociais, dos aplicativos de consulta de preço e dos novos intermediários nesse processo. No mercado de turismo, por exemplo, AirBnB e Expedia mudaram o mundo das viagens, provocando revisão nos modelos de negócio 
da hotelaria e das agências de turismo. No varejo, a Amazon, com uma eficiência na operação impressionante, já é a $10 .{ }^{a}$ maior varejista do mundo, segundo o relatório Global Powers of Retailing 2017, da consultoria Deloitte.

Hoje em dia, convivem jornadas de compras opostas. De um lado, cada vez mais varejistas adotam o "compre online e retire na loja", como é o caso do Carrefour e da Coop aqui no Brasil. No outro extremo, consumidores compram na loja, mas não levam o produto. É o caso da Bonobos, varejista online norte-americana de moda masculina que conta com 30 lojas, chamadas guideshops. Nesses locais, o cliente tem atendimento personalizado, prova as roupas, faz as compras e sai sem a mercadoria, que é entregue, sem custo, a partir de uma central de distribuição. Com vantagens operacionais imensas, níveis de estoque baixos e centralização em um único centro de distribuição, a loja física foca em atender bem os clientes e complementar a operação online. No Brasil, a Amaro, empresa de moda feminina, funciona da mesma forma que a Bonobos. Conta com 11 guideshops, promete mudança de coleção mensal, oferece entrega expressa em 2,5 h e faz troca e devolução com coleta em casa.

Não há indícios de que as novidades no processo de compra vão parar por aqui. Robôs atendentes, realidade virtual e realidade aumentada prometem mudar ainda mais a jornada de compras. Acompanhar todas essas transformações é fundamental.

\section{NOVAS INFORMAÇÕES PARA GERENCIAR}

$\mathrm{O}$ consumidor é frequentemente surpreendido pelo Google+, Facebook ou TripAdvisor solicitando-lhe a avaliação de um restaurante, hotel ou loja que acabou de visitar. Também vem sendo perseguido por anúncios de produtos ou serviços sobre os quais simplesmente fez alguma pesquisa na internet. A vida digital deixa muitos rastros e permite uma riqueza de dados sobre o cliente que beira a invasão de privacidade. Assim como os consumidores têm cada vez mais acesso a informações, as empresas varejistas também ganham poder com a junção de dados de navegação online, informações de compra e monitoramento do tráfego nas lojas.

A questão é como gerenciar tal volume de informações. Rebecca Minkoff, varejista de moda feminina dos Estados Unidos, consegue usar as novas tecnologias para captar informações e oferecer serviços adicionais aos clientes. $\mathrm{Na}$ entrada da loja, há uma gigantesca tela touch, que também faz a vez de espelho. Navegando nessa tela, os clientes podem acessar o catálogo da loja e indicar os produtos que gostariam de experimentar. Uma mensagem no celular cadastrado indica para qual provador devem se dirigir. Eles também podem solicitar gratuitamente água, chá, espumante ou café expresso, e recebem outra mensagem de texto tão logo a sua bebida esteja pronta.

Dentro do provador, a interação digital continua forte, com espelhos que também funcionam como telas sensíveis ao toque. $\mathrm{O}$ cliente pode mudar a iluminação, simulando a luz do dia, o entardecer, anoitecer etc. Como todas as mercadorias levam etiquetas de identificação por radiofrequência (Radio Frequency Identification - RFID), cada vez que uma nova peça é trazida para o provador, o sistema reconhece sua entrada, passando a apresentar sua imagem na tela. Uma grande vantagem do sistema é permitir ao varejista acompanhar os itens levados até o provador e que não foram comprados, os "carrinhos abandonados". Isso gera a possibilidade de follow-ups de vendas para os clientes. O acompanhamento das compras em detalhe também permite traçar perfis e tipologias de clientes.

Como se vê no exemplo de Minkoff, os dados estão sendo gerados em velocidade e quantidade antes inimagináveis são muitos e, às vezes, de difícil análise. O desafio hoje não é mais tê-los; é transformar tudo isso em informação útil.

\section{NOVO PAPEL DA LOJA FÍSICA}

Com a transformação da jornada de compras, há quem questione se, no futuro, precisaremos de lojas físicas. Dadas as inúmeras opções online, por que alguém deixaria o conforto de sua casa para visitar uma loja? Simplesmente porque a sua função vai mudar.

Há iniciativas hoje que sinalizam qual seria esse novo papel da loja física. Ao que tudo indica, esses espaços deverão ser transformados em ambientes em que o cliente pode "sentir" o posicionamento e a proposta da marca. Três casos recentes mostram como a nova loja pode ser.

A Samsung 837, localizada no Meatpacking District, em Nova Iorque, é o primeiro exemplo. Com cerca de $5.000 \mathrm{~m}^{2}$, a loja é a "manifestação física" da marca (note o termo que a Samsung utiliza para descrevê-la). A não ser pelos cafés e lanches do Stand Coffee, não é possível comprar outra coisa nessa loja. Em relação aos produtos Samsung, o máximo que a loja faz é indicar onde adquiri-los no varejo tradicional, partindo da ideia de que as pessoas já têm seus locais preferidos de compras.

Um dos pontos fortes da loja é um painel digital com 3 andares de altura e 96 monitores de 55 polegadas cada. Esse painel está instalado em um anfiteatro para eventos com capacidade para receber 75 pessoas. Nesse espaço, há também uma "estação selfie", que oferece aos visitantes a 


\section{CENTRO DE EXCELÊNCIA EM VAREJO FGV EAESP}

Criado em 2001, o Centro de Excelência em Varejo (GVcev) da FGV EAESP tem como principal objetivo contribuir para o desenvolvimento do varejo no Brasil, por meio de atividades voltadas à educação, à pesquisa e a eventos.

Multidisciplinar e próximo à comunidade empresarial, o centro busca harmonizar teoria e prática, estimulando o interesse e a participação dos estudantes no setor varejista. "Somos um braço de contato com o mundo empresarial. A intenção é incentivar os alunos a trabalharem no varejo e enxergá-lo como um setor em que podem fazer carreira”, afirma o professor Jacques Gelman, um dos fundadores do GVcev.

Entre as inovações do GVcev está o Congresso Latino-Americano de Varejo (CLAV), no qual alunos de mestrado e doutorado, do Brasil e do exterior, enviam seus artigos para serem avaliados e divulgados na EAESP. "Realizamos muitas atividades de disseminação do conhecimento, visando, principalmente, colaborar para a evolução do varejo brasileiro”, diz Gelman.

Outro diferencial do centro é o Programa Varejo Sustentável. Com grande impacto social, tem o intuito de estimular empresas varejistas a incorporar práticas sustentáveis em seus negócios. Desse programa, surgiu o primeiro Prêmio de Responsabilidade Social e Sustentabilidade no Varejo, que conta com a participação de instituições de diversos setores e permitiu à FGV ser pioneira na conscientização e disseminação de ações nessas frentes.

Para mais informações: cev.fgv.br

oportunidade de se ver no telão por alguns instantes, tempo suficiente para postar no Snapchat ou Instagram.

Além disso, a Samsung 837 oferece a possibilidade de o consumidor conhecer uma cozinha completa com produtos Samsung, incluindo uma geladeira conectada à internet. A loja também apresenta atrações que provocam filas: passeios turísticos por diversas regiões do planeta e jogos em realidade virtual. Segundo a própria Samsung, o estabelecimento tem gerado uma média de mil visitas por dia.

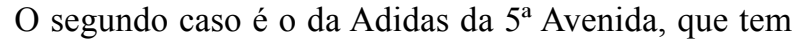
um cenário inspirado nos ginásios de esporte das escolas norte-americanas e já é atração turística em Nova Iorque. A entrada da loja assemelha-se com o túnel de passagem dos atletas do vestiário para o campo e os caixas lembram bilheterias esportivas. Há uma arquibancada na qual o cliente pode sentar, relaxar e observar o fluxo da rua. Os provadores parecem vestiários das arenas esportivas. Os visitantes são recepcionados por um "especialista em experiência do consumidor", colaborador treinado para contar a história do prédio, da marca e levar as pessoas para um tour em cada canto do estabelecimento.

Além disso, há um espaço dedicado à personalização de tênis que permite ao cliente experimentar cores, materiais e acabamentos. Também é possível testar os produtos em cestas de basquete, minicampos de futebol e esteiras. Numa pista de corrida, o consumidor pode mensurar com equipamento especial sem fio (o Run Genie) como está sua pisada, um serviço oferecido em parceria com uma empresa fornecedora das Forças Armadas norte-americanas.
O terceiro caso, a Livraria Cultura, mostra que há varejistas atentos a essa tendência no Brasil. Apesar de continuar comercializando livros e música, suas lojas incorporam teatros, espaços de convivência, cafés e até restaurantes, como é o caso do Manioca, na unidade do Shopping Iguatemi, em São Paulo. Essa mesma loja tem uma minicozinha equipada para receber chefs e especialistas para performances gastronômicas, degustações e eventos de culinária.

\section{EM RESUMO}

O varejo está enfrentando um momento de grandes desafios e possibilidades, mas há espaço para uma verdadeira reinvenção do setor. Para chegar lá, cada empresa tem que compreender o quanto a jornada de compras foi impactada pelas novas tecnologias e quais adaptações precisa fazer. Após esse entendimento, deve criar estratégias para que a equipe use da melhor forma a riqueza de dados e informações que hoje em dia os sistemas são capazes de gerar. Como último passo, é fundamental encontrar o novo papel da loja física nesse contexto digitalizado. No final das contas, o grande desafio do varejo parece ser continuar relevante na vida das pessoas.

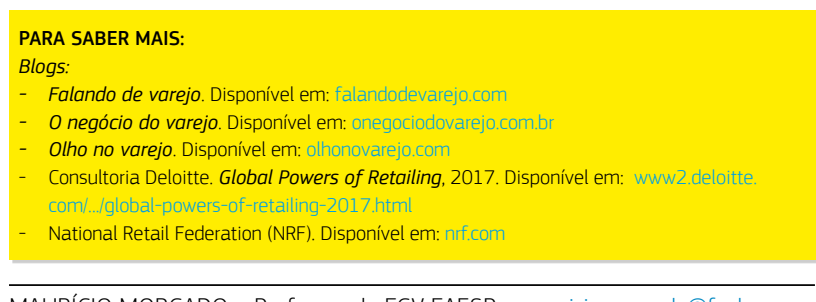

MAURÍCIO MORGADO > Professor da FGV EAESP > mauricio.morgado@fgv.br 